\title{
Ciência e interpretação: o problema do estatuto filosófico da psicanálise
}

Science and interpretation: the problem of the philosophical status of psychoanalysis

Ciencia e interpretación: el problema del estatus filosófico del psicoanálisis

\section{Carlos Roberto Drawin *}

\section{Resumo}

Este artigo tem como objetivo apresentar, de modo sucinto, alguns parâmetros para a discussão acerca do estatuto epistemológico da psicanálise. Com tal propósito, foi abordada a inter-relação entre hermenêutica e naturalismo, de modo a mostrar que a psicanálise não se enquadra inteiramente em nenhum dos dois modelos, se considerarmos o primeiro como um tipo de relativismo e de inflação do sentido e o segundo como um tipo de fisicalismo reducionista. Para aclarar a singularidade da psicanálise, foram feitas algumas consideraçôes históricas sobre o naturalismo freudiano e algumas consideraçóes filosóficas de cunho epistemológico e ontológico sobre a semântica da natureza e seus limites.

Palavras-chave: Filosofia. Psicanálise. Ciência. Epistemologia.

\begin{abstract}
This paper aims to present succinctly some parameters for discussion about the epistemological status of psychoanalysis. With that purpose addressed, the relationship between naturalism and hermeneutics was analyzed. In order to show that psychoanalysis does not fit entirely in either of the models if we consider the first as a kind of relativism an inflation of the sense and the second as a kind of reductionist physicalism. To clarify the uniqueness of psychoanalysis some historical considerations on Freudian naturalism were made. Philosophical, epistemological and ontological perspectives were also taken into consideration concerning the semantic of nature and its limits.
\end{abstract}

Keywords: Philosophy. Psychoanalysis. Science. Epistemology.

\footnotetext{
Doutor em Filosofia pela UFMG; docente do Programa de Pós-graduação em Filosofia na UFMG; docente do Programa de Pós-graduação em Filosofia na Faje, em Belo Horizonte-MG; psicólogo e psicanalista. E-mail: carlosdrawin@yahoo. com.br.
} 


\section{Resumen}

Este artículo tiene como objetivo presentar sucintamente algunos parámetros para la discusión sobre el estatuto epistemológico del psicoanálisis. Con este propósito se abordó la interrelación entre hermenéutica y naturalismo para demostrar que el Psicoanálisis no encaja totalmente en ninguno de los dos modelos si consideramos el primero como un tipo de relativismo y de inflación del sentido y el segundo como una especie de fisicalismo reduccionista. Para aclarar la singularidad del psicoanálisis se hicieron algunas consideraciones históricas sobre el naturalismo freudiano y algunas consideraciones filosóficas de cuño epistemológico y ontológico sobre la semántica de la naturaleza y sus límites.

Palabras clave: Filosofia. Psicoanálisis. Ciencia. Epistemología

\ verdade é sempre parcial, nos diz Slavoj Zizek, por isso a pretensão de imparcialidade é vã e nos resta aceitar que a nossa interpretação do Imundo é uma "leitura partidária", uma vez que o mundo não é uma coisa que está dada, mas um interminável entrecruzamento de interpretaçôes. Por isso inicio o meu texto tomando partido em relação à psicanálise, por meio de duas crenças muito simples, genéricas e sucintas:

a) a primeira, que pode ser definida como externa ao campo psicanalítico, é a crença na relevância científica e cultural da psicanálise justamente numa época que tem reiteradamente anunciado o seu declínio e o seu fracasso diante dos avanços das neurociências, da psicofarmacologia e da psiquiatria biológica;

a) a segunda, que pode ser definida como interna ao campo psicanalítico, é a crença no caráter plural do que normalmente designamos no singular como psicanálise. Essa pluralidade não se confunde com uma multiplicidade dispersiva, mas constitui algo como um campo ou como um conjunto de teorias cujo "ar de família" remete, em última instância, ao texto freudiano tomado em seu caráter fundacional, ainda que em diferentes perspectivas interpretativas. Embora sem concessões ao ecletismo, creio que a reivindicação de ortodoxia e hegemonia por qualquer uma das vertentes que compóem o campo 
psicanalítico apenas exacerba a pequena rivalidade narcísica entre elas e em nada contribui para aprofundar a presença cultural da psicanálise.

Essas convicções convergem um mesmo interesse crítico em relação a uma civilização que parece ter mergulhado numa crise generalizada, na qual a homogeneização da sociedade produzida por imperativos técnicos, econômicos e administrativos tem como contrapartida a fragmentação da cultura decorrente do declínio das grandes narrativas e dos antigos referenciais simbólicos. Nessa época em que o pensamento parece ter se tornado obsoleto diante do curso inexorável dos acontecimentos a psicanálise, herdeira do vigor especulativo da Europa Central no século XIX, tornou-se um elemento imprescindível na construção de uma teoria crítica da cultura. Afinal de contas, essa é a ideia que me mobiliza no meu compromisso com a psicanálise, ao concebê-la um foco de pensamento vivo e resistente numa civilização que tende a neutralizar o empenho crítico e reflexivo e trata como irrelevante tudo o que não pode se apresentar imediatamente como capaz de ser operacionalizado. Por isso a sempre anunciada "morte da psicanálise" atesta, como diz Derrida \& Roudinesco (2004), "a compulsão a enterrar vivos os estraga-prazeres inoportunos" (p. 211), aquilo que ameaça o que se pretende sólido, estável, monolítico. Por isso, observa o filósofo francês, essa psicanálise tantas vezes enterrada e considerada como descartável ainda suscita medo,

pois a "lógica do inconsciente" permanece incompatível com o que define a identidade do ético, do político e do jurídico nesses conceitos, mas também em suas instituições, e portanto em suas experiências humanas. Se levássemos em conta seriamente, efetivamente, praticamente, a psicanálise seria um terremoto quase inimaginável. Indescritível. Mesmo para os psicanalistas (Derrida \& Roudinesco, 2004, pp. 211- 214).

Não obstante o tomar partido não implica a aceitação inevitável da leitura sectária, pois esta se faz justamente a partir da ocultação do ponto de partida e dos pressupostos levando à inconsistência óbvia de uma perspectiva que se quer colocar sub specie totalitatis. Essa contradição de se reivindicar como a parte que contém o todo se dá na forma de um acesso privilegiado ao real, cuja certeza parece provir da arraigada convicção de que êxito cultural é também um índice da verdade. Dois exemplos fáceis podem ilustrar a força dessa convicção. No mundo ocidental pré-moderno, aquele caracterizado por uma "imagem de mundo" anterior às profundas transformaçôes do modo de pensar ocorridas nos séculos XVII e XVIII, a hegemonia da religião cristã parecia demonstrar a sua incontestável verdade. De modo semelhante, no 
mundo moderno, aquele caracterizado pela rápida ascensão e domínio cultural das Ciências da Natureza e de seu ideal metodológico, a religião e a metafísica antiga são vistas como meras "projeçōes antropomórficas" na realidade que apenas seria acessível em si mesma por meio dos procedimentos rigorosos e desmistificadores da ciência (Taylor, 1975, pp. 3-11).

Com o avanço avassalador da imagem científica do mundo, a Filosofia, tendo sido destituída de seu lugar de centro do sistema do saber, reafirmase em sua função crítica ao mostrar a impossibilidade de se alcançar cognitivamente a realidade em si mesma. Por isso Kant, ainda no limiar do grande triunfo cultural das Ciências da Natureza, procurou traçar os seus limites, definindo os diferentes interesses que subjazem ao trabalho da razão, e o fez não somente para assegurar a legitimidade da ciência dentro de tais limites, mas também para descortinar o horizonte do uso puro da razão que não é outro senão a ordem prática, ou seja, a realização ética da humanidade (Kant, 1985, pp. 633-638). Por isso, em meados do século XIX, num momento em que o cientificismo parecia atingir o seu clímax e a polêmica antifilosófica recrudescia na esteira do refluxo do Idealismo Alemão, ressurge como palavra de ordem a necessidade de retomar a crítica kantiana da ciência. Esse "retorno a Kant" (die Rückwendung zu Kant) foi proclamado por Otto Liebmann, em sua obra de 1895, "Kant e os epígonos", que concluía cada capítulo após discutir a situação filosófica de sua época com a frase: "assim a volta a Kant é necessária” (Röd, 1996, pp. 347-350). Esse apelo cristalizava um sentimento de insatisfação em relação ao reducionismo naturalista que então se disseminava na cultura científica da época e se vulgarizava num materialismo grosseiro como o do médico Ludwig Büchner que, em seu livro de 1855, "Força e matéria", identificava a mente com o conjunto das funções cerebrais descritas pela fisiologia e que se resumia na célebre frase de Karl Vogt, em seu escrito de 1854, "Fé de carvoeiro e ciência": "As ideias estão com o cérebro na mesma relação que a bílis com o fígado ou a urina com os rins" (como citado em Coreth, Ehlen \& Schmid, 1987, pp. 149-151).

A psicanálise, como veremos, nasceu envolvida nesse clima intelectual e se desenvolveu com Freud alheia a uma revolução que despontava: a da consciência histórica emergente que, a partir do século XX, iria se propagar rapidamente, colocando em cheque não só o ideal metodológico das Ciências da Natureza, mas a possibilidade de se alcançar uma objetividade acima da multiplicidade das perspectivas em conflito. De qualquer forma, podemos falar genericamente que, a partir daí, instalou-se uma forte contraposição, que ainda permanece, entre o reducionismo naturalista e o relativismo historicista. A hermenêutica surgiu lentamente como a busca de uma rota 
capaz levar a frágil nau da razão para além desses dois escolhos: o naufrágio do sujeito, sucumbindo à concepção fisicalista da natureza; e o naufrágio da ciência, afogando no entrechoque das perspectivas incomensuráveis. Num breve texto de 1900, o filósofo alemão Wilhelm Dilthey traça o percurso do nascimento da hermenêutica desde as discussóes gregas acerca da retórica, passando pela exegese bíblica da reforma protestante até chegar à obra seminal de Schleiermacher, que propunha elevar a arte da interpretação ao nível de uma ciência universal. Ou seja, se todos os conhecimentos humanos são constituídos historicamente e se configuram em contextos particulares, em singularidades culturais, então só se pode estabelecer o estatuto epistêmico do conhecimento se nele incorporarmos essas condições que o constituem. Desconhecer essas condições históricas de possibilidade não produz objetividade, mas apenas levaria inexoravelmente à ilusão de um positivismo ingênuo e não seria o melhor meio de combater o relativismo. Algumas décadas mais tarde, Gadamer retoma e aprofunda em sua obra magna, "Verdade e método", o confronto entre a exigência hermenêutica e a sua escamoteação por um método anistórico: na história efetiva do saber (Wirkunggeschichte), há uma polarização entre o texto que nos é transmitido, que nos foi legado pela tradição (interpretandum), e o contexto de sua recepção por um leitor condicionado por sua pré-compreensão (interpretans). Assim, o "círculo hermenêutico" enfatiza a distância e o estranhamento (Fremdheit) entre o texto transmitido e o contexto de sua recepção não como proclamação de uma tese relativista, mas como procedimento para explicitar e sustentar a sua pertinência dialógica (Zugehörigkeit). O historicismo relativista $\mathrm{e}$ o racionalismo objetivista participam do mesmo prejuízo ou do mesmo preconceito (Vorurteil), que consiste em julgar apenas negativamente todo prejuízo ou todo preconceito, como se eles fossem simplesmente sinônimos de um juízo sem fundamentação. No entanto o prejuízo deve ser levado em conta e examinado como condição necessária e incontornável de toda compreensão (Thouard, 2004, pp. 169-184; Gadamer, 1977, pp. 331-337).

Essas considerações parecem apontar para uma divisão dos domínios do conhecimento que pode facilmente se deslocar para uma hierarquia dos saberes em que, de um lado, estão as ciências em sentido forte, cujo objetivo seria apreender a realidade natural em si mesma, independentemente da mente que a apreende; e, de outro lado, as ciências fracas porque fracassam sempre em sua pretensão de objetividade enredadas que estão em suas aporias epistemológicas em cujo núcleo se encontra a categoria de subjetividade. Não obstante, a hermenêutica após Heidegger não iria restringir-se à sua função metódica como critério de demarcação do campo científico entre as Ciências 
da Natureza como conhecimento guiado pela explicação, pelo descobrimento das conexôes causais efetivas, e as Ciências do Homem como conhecimento guiado pela compreensão, pela escavação das diferentes camadas de significação. A compreensão estaria radicada no próprio ser do homem: "é próprio desse ente, com seu ser e por seu ser, o estar aberto para ele mesmo. O entendimento do ser (Seinsverständnis) é ele mesmo uma determinação do ser (Seinsbestimmtheit) do Dasein" (Heidegger, 2012, p.59). Ou seja, a compreensão não é um método das Ciências do Homem e sim constitutiva do ser deste ente, o homem, que compreende a totalidade dos entes (Drawin, 2009, pp. 45-60). Por isso, Gadamer não vacila em afirmar claramente o alcance ontológico e não apenas metódico da hermenêutica, pois o que está em jogo na linguagem não diz respeito apenas à "atividade metodológica do sujeito", e sim, como na dialética antiga, um

acontecer da coisa mesma, um "acontecer" que o pensamento padece... $\mathrm{O}$ ser que pode ser compreendido é linguagem. $\mathrm{O}$ fenômeno hermenêutico atribui aqui sua própria universalidade à constituição ôntica do compreendido quando a determina num sentido universal como "linguagem" e quando entende sua própria referência ao que é como interpretação. Por isso não falamos somente de uma linguagem da arte, mas também de uma linguagem da natureza e inclusive de uma linguagem das coisas (Gadamer, 1977, pp. 567-568).

Certamente seria importante discutir criticamente essa concepção radicalizada da hermenêutica, que lhe atribui um alcance ontológico. Não obstante, o que queremos ressaltar é que, nessa perspectiva a hermenêutica, distancia-se decididamente do historicismo relativista e se abre à possibilidade da verdade, ou seja, da ideia de que a linguagem não é uma barreira intransponível a enclausurar o sujeito em si mesmo, mas toca o real, apesar de não apreender exaustivamente o seu sentido. Por outro lado, a hermenêutica é apresentada em frontal contraposição com o naturalismo que, em suas diversas ramificações, têm em comum a pretensão de abordar o fenômeno humano segundo os mesmos padrões epistêmicos que se tornaram prevalentes nas Ciências da Natureza após a revolução científica do século XVII. Trata-se de uma opção metafísica cujo núcleo consiste na eliminação, por princípio, de todas as propriedades consideradas como antropocêntricas e, portanto, redutíveis a um estatuto epifenomênico em relação àquelas propriedades consideradas como "absolutas" porque independentes de todas as dimensões características da experiência humana enquanto tal como consciência, linguagem, intencionalidade, sentido, valor, autointerpretação, etc. Um 
exemplo típico dessa concepção encontra-se na distinção entre as qualidades primárias, que seriam como massa, extensão ou força que são passíveis de tratamento matemático e qualidades secundárias que seriam aquelas dependentes das disposições subjetivas na apreensão de determinados fenômenos, como gostos, cores, cheiros, sensaçôes de frio ou calor, etc. As primeiras pertencem às coisas mesmas, enquanto as segundas se restringiriam à captação antropomórfica da realidade (Taylor, 1985, pp. 1-12; Audi, 2006, pp. 781-782).

Essa visão depreciativa da hermenêutica, considerada sumariamente como uma forma de relativismo e irracionalismo, desconhece não só a intenção epistemológica de seus procedimentos, mas, sobretudo, a sua orientação ontológica. Por outro lado, no contexto polêmico em torno dos métodos explicativo e compreensivo, forjou-se uma ideia bastante simplificada do naturalismo como opção metafísica inerente às Ciências da Natureza. O desconhecimento recíproco é propício a esse jogo imaginário em que a hermenêutica se confunde com o relativismo ou com a inflação de sentido própria às filosofias da consciência e a exigência de cientificidade se confunde com o positivismo ingênuo, com um naturalismo ansioso em aceder ao real aquém e independente da experiência humana.

No entanto, observa Clifford Geertz (2001), criticando as referências de Charles Taylor acerca da "ciência natural", a homogeneização apressada da ciência na forma de um naturalismo reducionista como posição a ser combatida acaba por se tornar numa espécie de complemento e confirmação da idealização positivista da ciência concebida como um bloco monolítico, como um continente metodológica e objetivamente uniforme. Porém a ciência moderna da época da revolução científica do século XVII não é a mesma da segunda revolução científica do século XIX, que estabeleceu a ciência como organização institucional e como gênero cultural a serviço de uma humanidade a caminho de sua realização. Essa transformação histórica também se projeta no século XX, no que poderia ser denominada como uma terceira revolução científica que impõe aos que investigam a História das Ciências noções como as de rupturas, desvios, descontinuidades, dispersão e dissenso. Essa pluralidade se torna patente nas visões dissidentes dos cientistas acerca da relação entre sua prática científica com concepções epistemológicas supostamente consensuais. Assim, por exemplo, o neurofisiologista e imunologista Gerald Edelman argumenta contra a rejeição liminar da mente, da consciência e da intencionalidade no domínio da ciência natural. Do mesmo modo, argumentam eminentes representantes da Filosofia da Ciência, como 
Thomas Kuhn ou Paul Feyerabend, para quem o reducionismo fisicalista não pode nem ser demonstrado e nem tomado como uma pressuposição necessária, mas é apenas uma crença. Segundo ele,

a ciência possui vastas lacunas; suas alegadas unidade e abrangência não são fato e sim suposição (metafísica); e aquelas dentre suas projeções que funcionam provêm de áreas isoladas e consequentemente carecem do poder destrutivo a elas atribuído. Elas mostram como certos setores do mundo respondem às cruas abordagens; elas não nos dão pista sobre a estrutura do mundo como um todo (Feyerabend, 2005, p. 192).

Por isso Geertz (2001) sugere que as Ciências da Natureza não formam um continente, um bloco monolítico, mas uma espécie de arquipélago composto de ilhas de diversos tamanhos que estão mais ou menos isoladas ou mantém relações complexas e ramificadas e é constituído por diferentes comunidades de pesquisadores e retoma perguntas formuladas por Richard Rorty: "Que método é comum à paleontologia e à física das partículas? Ou, qual é a relação com a realidade compartilhada pela topologia e pela entomologia?" (citado por Geertz, 2001, p. 137). Nessa perspectiva, caracterizar de maneira genérica o suposto "modelo da ciência natural" sob a rubrica naturalismo é problemático, a não ser quando nos propomos a fazer um questionamento daquilo que pode ser chamado de "discurso da ciência", que é justamente a operação através da qual a unidade imaginária da ciência passa a ser utilizada como instância de legitimação ideológica (Geertz, 2001, pp. 131-148; Drawin, 2004, pp. 28-42).

Essas considerações têm por objetivo esboçar um quadro a partir do qual o estatuto epistemológico da psicanálise possa ser inicialmente caracterizado. Certamente o problema da singularidade epistêmica da psicanálise, em decorrência de suas imensas dificuldades, não pode ser diretamente enfrentado num pequeno artigo. Limitei-me aqui a propor duas ideias a serem posteriormente desenvolvidas. A primeira delas diz respeito à hermenêutica identificada com o historicismo e colocada como antagônica à psicanálise. Afinal, a hermenêutica e a fenomenologia seriam filosofias da consciência incompatíveis com a ciência do inconsciente. Ao contrário, acredito que algumas aporias enfrentadas pela teoria psicanalítica poderiam ser aclaradas por meio da aproximação com a filosofia hermenêutica que, como vimos, em sua orientação ontológica, mostra como a linguagem se tece continuamente em torno de um núcleo duro ou de algo como uma coisa em si (das Ding) que não se deixa apreender numa rede de significações e nem se dissolve por meio de uma atribuição de sentido. A segunda delas diz respeito ao naturalismo 
frequentemente identificado como uma pressuposição inevitável das Ciências da Natureza e referido redutivamente a uma realidade exterior à experiência humana e resistente a todas as tentativas de assimilação antropomórfica. Ao contrário, acredito que o naturalismo é uma derivação ideológica de uma concepção de natureza construída como objeto adequado a certos parâmetros metodológicos convenientes a determinados programas de pesquisa, mas que não esgota outras interpretações alternativas acerca da natureza. Em síntese, nem a hermenêutica é tão "hermenêutica" como se pensa, isto é, como uma hipertrofia de sentido desatenta ao real que resiste a todas tentativas de interpretação, nem o naturalismo é uma pressuposição inerente às Ciências da Natureza que, em seu afã de objetividade e de formalização matemática, apreenderia um real como pura exterioridade em relação à linguagem. Desse modo, parece-me viável procurar entender o estatuto epistemológico da psicanálise como um sutil entrecruzamento de hermenêutica e naturalismo a ser investigado no plano metapsicológico, no plano da estrutura conceitual da teoria e não apenas como influências intelectuais relevantes para a compreensão da formação do freudismo. Para que essa investigação dê frutos e possa suscitar reflexóes e discussóes comuns no campo psicanalítico, o primeiro obstáculo a ser afastado, e já mencionado nas crenças sumárias com que iniciei este artigo, é romper os muros defensivos que cercam os guetos institucionais. Neles a imagem da psicanálise se aproxima perigosamente da idealização positivista da ciência, porém na figura especular invertida de um saber imunizado contra toda crítica, mas não em decorrência de sua segurança metodológica e de seu êxito social, como no caso das ciências duras, mas porque a sua verdade somente se revela àqueles que a cultivam e a ela já aderiram previamente. Nada mais estranho à psicanálise do que essa coincidência quase imediata entre certeza e verdade, justamente porque, entre a experiência singular da análise e a elaboração conceitual da teoria, há uma distância intransponível que ora destitui as certezas da experiência e ora desmonta as verdades da teoria. Essa distância intransponível nada tem a ver com a preguiça intelectual, mas ao contrário, impulsiona o árduo esforço das mediaçôes conceituais que não podem ser substituídas por um jargão hermético que se converte, como observa Guy Duportail, numa espécie de latim eclesiástico a suscitar o fascínio e a reverência dos noviços e iniciados. Ao ceder a tal inclinação cômoda, a psicanálise substitui a elucidação reflexiva e crítica pelos vínculos transferenciais e desliza para uma forma vulgar de psicologismo no qual a efetividade da certeza triunfa sobre a transcendência do conceito. $\mathrm{O}$ resultado desse deslizamento não pode ser outro senão o conformismo existencial e a abdicação do pensamento (Duportail, 2003, p. 9-31). Ou seja, o risco de um esoterismo que insiste na linguagem da "falta" 
e da "castração", do "impossível" e do "real", e as considera como verdades já possuídas e não como a inquietação proveniente da necessidade de "pensar no incomensurável”, como observou agudamente Ansermet:

Se a psicanálise é uma obra aberta, inacabada, ela se encontra em uma relação de necessidade e de alteridade com outros campos, inclusive com a ciência - com a condição ao menos de que se trate de uma versão da ciência que mantenha aberta a questão de seu ponto de impossível (Ansermet, 2013, p.46).

O desdobramento dessas ideias preliminares levaria a uma argumentação longa e atravessada por muitas pressuposições filosóficas que precisariam ser explicitadas e discutidas, como procurei fazer anteriormente (Drawin, 2005). Obviamente esse não é o caso, e por isso me atenho a três observações que, por seu caráter ligeiro e por se desviarem do curso principal da argumentação, bem podem ser designadas como digressóes: a primeira se resume a uma breve referência acerca da formação científica de Freud; a segunda, a elementos para uma discussão filosófica acerca da relação semântica e natureza; a terceira se resume nas poucas frases do que chamei de digressão conclusiva.

\section{1a digressão: o naturalismo freudiano}

A fundação da psicanálise resulta de múltiplos fatores culturais e influências científicas e filosóficas. Um estudioso do assunto não poderia omitir a atmosfera típica da cultura vienense na segunda metade do século XIX e nem a tradição científica alemã, não poderia deixar de lado a medicina romântica, as filosofias da natureza, o impacto do evolucionismo, os intensos debates nas áreas da fisiologia, da neurologia e da psicopatologia, bem como deveria precisar a velada influência kantiana e a o papel crucial da metafísica de Schopenhauer (Rocha, 2004, pp. 45-64). A lista poderia prosseguir, e os estudos especializados, cada um seguindo esses e outros aspectos marcantes na gênese da psicanálise, proliferam numa literatura que testemunha, na diversidade das abordagens, a originalidade do pensamento freudiano. Este não se dissolve nas influências que o condicionaram, pois sua originalidade não depende de uma criação a partir do nada, mas sim na interpenetração complexa desses elementos tão heterogêneos. Eu gostaria de ressaltar, porém, como a doxa freudiana, isto é, as suas opiniōes filosóficas e a sua consciência epistemológica explícita, joga um papel ambivalente na constituição da episteme psicanalitica, isto é, na lenta construção teórica da metapsicologia, que vai além de sua obra para se projetar na história de um campo científico. Quando 
examinamos as suas crenças mais imediatas, nelas podemos identificar facilmente a sua adesão aos princípios da Escola Fisicalista de Berlim, cujo credo central pode ser caracterizado como um tipo de naturalismo fortemente reducionista: todos os fenômenos humanos, inclusive aqueles tradicionalmente definidos como "mentais" ou "espirituais", podem ser remetidos aos processos físico-químicos subjacentes (Assoun, 1983, pp. 45107). Essa orientação básica funciona como um obstáculo epistemológico para a proposição de uma teoria da mente cada vez mais independente da linguagem e dos referenciais biológicos que, no entanto, permanecem até o fim como um recurso científico idealizado diante das dificuldades crescentes da metapsicologia, sobretudo após a crise da primeira tópica. Por outro lado, essas mesmas crenças que compõem o tosco naturalismo freudiano o impediram de se tornar um "terapeuta", um "curador" na linha dos médicos da alma da medicina romântica. A presença do naturalismo teria especial relevância no contexto do combate cultural (Kulturkampf) que então se travava no universo intelectual da Europa Central e na difícil ascensão da ciência num meio acadêmico ainda fortemente marcado pelo lugar central da Filosofia. Pode-se perceber, então, como o obstáculo epistemológico representado pelo naturalismo também representa uma valiosa estratégia para que o saber nascente escapasse tanto da anexação filosófica quanto da diluição na fisiologia e se demarcasse, seja da teoria sexual delirante de Fliess, seja do furor classificatório da sexologia médica. Como seguir nesse caminho tortuoso sem reivindicar a positividade de um discurso capaz de pairar acima do infindável conflito das interpretaçôes e onde encontrar esse lugar transcendental senão num naturalismo que pudesse resistir à vertigem do abismo hermenêutico?

O naturalismo cumpriu uma função estratégica na autoafirmação da nova ciência, mas a ela não se restringiu, porque, no nível da episteme psicanalítica, descolada da doxa freudiana, o naturalismo não mais se identificava com a natureza pensada como objeto das Ciências da Natureza, porque este seria apenas um correlato do sujeito epistêmico centrado na primazia da consciência. Ou seja, as Ciências da Natureza concebidas à luz do simples empirismo traria consigo, como Husserl demonstrou magistralmente, um psicologismo mais ou menos explícito e inevitavelmente autocontraditório (Husserl, 1982, pp. 109-163).

Desse modo, o naturalismo típico da consciência epistemológica de Freud levaria ao relativismo cético e não poderia contribuir para a construção de uma ciência do inconsciente, uma vez que esta é incompatível com o psicologismo. Esse risco do psicologismo permaneceu sempre presente 
na história da psicanálise, e o seu fantasma foi justamente combatido pela via da rejeição da hermenêutica. Não obstante, como tentei mostrar nas consideraçōes introdutórias deste artigo, a vulgata hermenêutica, representada pela inflação da linguagem e do sentido, pode ser vista como um complemento do naturalismo reducionista que traveste como sendo o real em última instância, o que é simplesmente uma interpretação certamente legítima e fecunda, mas bem circunscrita, de um conjunto de programas de pesquisa.

$\mathrm{O}$ que Freud foi descobrindo em sua investigação não foi a realidade natural presente no homem, mas um "fundo" não determinável como um objeto qualquer, um vórtice cuja nomeação impossível não se oferece como uma positividade a ser apreendida, mas como pura negatividade em torno da qual circulam as representaçôes e os discursos. Essa "coisa mesma" aparece de modo encoberto na adoção muito menos incômoda da positividade fisicalista, pois esta lhe servia como um álibi para descartar as indagações metafísicas e mascarar como ciência normal aquilo que apenas se deixava vislumbrar como inquietação e angústia. Ao transgredir os limites da epistemologia de sua época e ao desconhecer a "polêmica dos métodos" (Methodenstreit) desencadeada no universo filosófico alemão, Freud trilhará um deslocamento semântico irreversível que o levará a abandonar em "Sobre a concepção das afasias" (1891) a neurologia localista e à lenta transformação metapsicológica operada desde o "Projeto de uma psicologia" de 1895 e consolidada na "Carta 52" e no capítulo VII da "Interpretação dos sonhos". Certamente esse deslocamento só poderia ser seguido na confrontação entre a letra do texto freudiano, a sua rigorosa exegese e as hipóteses interpretativas suscitadas pelo desenvolvimento posterior da obra e à luz da história da psicanálise. Em todo caso, poderse-ia propor, em princípio, que o naturalismo freudiano não encaminhou a psicanálise na direção do enquadramento nas Ciências da Natureza. Ao contrário, a esperança numa explicação biológica e a evocação da filogênese levam a teoria do inconsciente a um desvio crescente do modelo hegemônico de cientificidade que culmina na estranha noção de pulsão de morte. $\mathrm{O}$ naturalismo freudiano, assumido como uma atitude epistemológica comum à ciência de seu tempo e tributária do fisicalismo e do evolucionismo dos seus mestres vienenses, talvez possa ser compreendido mais adequadamente se recorrermos à "metafísica da vontade" de Schopenhauer, a quem Freud nomeou como precursor, especificamente em relação à ideia de pulsão, à ontologia hermenêutica de Heidegger e mesmo à filosofia lévinasiana da alteridade. 


\section{2a digressão: a semântica da natureza}

A ciência moderna não surgiu de modo abrupto no cenário intelectual do século XVII, mas o seu impacto na cultura europeia foi tão extenso e profundo que os historiadores passaram a designá-la como "revolução científica", recorrendo a um termo proveniente da história política. O modelo da ciência galileana não surgiu como um deus ex machina das observações dos fenômenos naturais e dos experimentos científicos, mas foi sendo gerado como um conjunto de pressuposições em direta contraposição com a física aristotélica. Essa não é uma ciência autônoma porque se articula intimamente com a metafísica e nela podemos encontrar uma hierarquia do mundo dentro da qual o homem não ocupa a posição mais importante senão a de um ser limítrofe conforme alcança a contemplação da totalidade cósmica, apesar de estar aprisionado no mundo sublunar, na esfera inferior dessa mesma totalidade. Não há, na cosmologia clássica e no geocentrismo, alguma arrogância antropocêntrica a reivindicar a centralidade da morada humana uma vez que os homens vivem "aqui embaixo", separados das esferas perfeitas do mundo supralunar (Brague, 1990, pp. 203-223). Assim, a "parábola copernicana" de Freud (tomada quase literalmente de Ernst Haeckel) pode ser uma boa ilustração da teoria do narcisismo em sua implicação cultural, mas não pode servir como referência histórica confiável. A revolução científica não assestou um "golpe cosmológico" no narcisismo humano seguido pelo "golpe biológico" darwiniano e pelo "golpe psicológico" desferido pela psicanálise. O "ingênuo amor-próprio da humanidade", como ele diz, teria sido duas vezes ferido pelas Ciências da Natureza e uma terceira vez pela psicanálise situada nessa mestra tradição científica (Freud, 1999a, pp. 294-295; Freud, 1999b, pp. 3-12).

No que diz respeito à metafísica e à cosmologia clássicas, a grandeza do homem reside em sua inteligência espiritual, mas esta só pode apreender a inteligibilidade do real porque está ancorada no ser ou, segundo Platão, porque haveria uma afinidade (Synggeneía) entre a alma intelectiva (nous) e o kosmos inteligível (noeton). Essa concepção platônica iria desencadear uma discussão filosófica complexa que atravessou os séculos e cujo primeiro grande capítulo (a teoria aristotélica do conhecimento) não levou a uma ciência sistemática inteiramente integrada e consistente, mas a uma sistematização "fraca", sempre atenta ao movimento e à multiplicidade do mundo, e como um feixe de saberes dotado de estrutura analógica. Por sua vez, a Física moderna se caracterizou pela intensa geometrização da natureza, por seu caráter construtivo, referido sujeito epistêmico como ponto de unificação do saber que, no entanto, permanece inquestionado quanto ao seu ser. 
Assim, desde as "Regras para a direção do espírito" (1628) de Descartes, vai se estabelecendo o primado da epistemologia sobre a ontologia e a formação, sob essa primazia, de uma ontologia encoberta (ontologie grise) cujo núcleo conceptual se expressa na fórmula de uma egologia: ego autem substantia (eu, no entanto, substância) (Marion, 1975). Ao colocar o Eu no lugar da substância aristotélica, a Filosofia moderna explicita o que já está pressuposto na nova ciência. A "revolução copernicana" não significou, portanto, um duro golpe no narcisismo humano, como quer Freud, mas o lento descortinar de uma nova época na qual o homem não mais necessita se interrogar como sujeito porque já se tem como certo que a natureza é um objeto a ser desmontado, reconstruído e controlado pelo homem. Nessa perspectiva, a natureza longe de ser um índice de um real simultaneamente incontornável e inominável, a natureza como objeto de ciência foi transposta numa linguagem formalizada e distanciada da linguagem ordinária, mas, mesmo assim, movida pelo ideal da transparência e da explicação exaustiva. O questionamento da correlação supostamente evidente entre ciência e natureza supõe a diferenciação dos diversos níveis semânticos em que a natureza pode ser interpretada. Segundo Mutschler, não precisamos aceitar sempre que o "mundo" é a "natureza" e que esta é o que as Ciências da Natureza dizem que ela é ao fornecer uma imagem do ser do mundo irreversivelmente orientada pelo fisicalismo. Para ele, podemos distinguir ao menos quatro tipos de interpretação filosófica da natureza (Mutschler, 2008):

a) a natureza como totalidade de tudo o que existe e que seria mero correlato da Ciência da Natureza;

b) a natureza como totalidade de tudo o que existe, mas que deve ser compreendida de maneira pluralista, uma vez que abrange domínios irredutíveis entre si, como arte, moral, linguagem, etc.;

c) a natureza como uma região determinada da realidade, mas que não abrange tudo o que existe, mas cuja região de objetos é investigada pela Ciência da Natureza. O que implica que o homem, como sujeito e, especialmente, como sujeito cognitivo e existencial, ultrapassa a região de objetos investigada pela Ciência da Natureza;

d) a natureza como uma região determinada da realidade, que não abrange tudo o que existe, e que pode ser abordada numa pluralidade de perspectivas. 
O naturalismo reducionista elege a primeira alternativa como a única racionalmente admissível e, ao fazê-lo, produz um estranho efeito, a de uma semântica que se nega como tal, pois a ciência supostamente visaria a uma realidade independente do "mundo da vida" (Lebenswelt) e do conflito das interpretações.

Como mostrou, de modo convincente, Lorenz Puntel, qualquer concepção teórica só pode ser construída num "quadro referencial" que contenha uma linguagem, uma lógica, uma semântica e uma ontologia. Todo empreendimento teórico remete a certa expressabilidade do real, e a linguagem como sistema semiótico composto por uma quantidade infinita de expressôes é o "meio" ou a instância dessa expressabilidade. Porém a linguagem não é um conjunto aberto e caótico de elementos que se sucedem, mas se apresenta como estrutura (conjunto de elementos e relações) que podem ser estruturas formais (lógicas e matemáticas) e de conteúdo (semânticas e ontológicas). A dimensão semântica é essencial, porque as expressões linguísticas significam e expressam algo, e, tendo um caráter proposicional, põe-se como plano da configuração linguagemmundo. A crítica da semântica das sentenças declarativas do tipo "Sp", a semântica composicional que leva a uma ontologia substancialista, nos incita na direção de uma experiência originária antepredicativa, mas sempre, e de qualquer forma, também nos incita na busca de semânticas alternativas (Puntel, 2008; Herrero, 2012). A pretensão de eliminar do discurso as estruturas semânticas também elimina a sua função mediadora entre a linguagem e o ser, o que nos conduz não ao puro enigma diante do qual nos caberia calar, mas à apreensão imediata do ser, uma espécie de conhecimento inefável que seria o domínio por excelência do imaginário. O cultivo atual da "diferença pura" produz amiúde o efeito indesejado da afirmação de uma identidade imediata numa espécie de inflação do sentido, numa abdicação das mediações que favorece uma espécie de obscurantismo crítico, uma noite em que "todos os gatos são pardos". Não é difícil compreender, portanto, porque a psicanálise, ao enfatizar os limites do sentido e investigar os confins da semântica, caia na armadilha do imaginário e se deixe enredar por novas formas de psicologismo. Por outro lado, a psicanálise não pode abandonar esse ir de encontro aos limites da linguagem e apontar para o outro lado, o lado quase indizível que subjaz ao nosso esforço de dar sentido às coisas e às nossas vivências, não pode deixar de marcar o lugar vazio que não pode ser preenchido nem pela intuição e nem por um ato de significação. Esse é um ponto crucial e difícil de ser abordado, porque, ao fazê-lo, e não podemos deixar 
de fazê-lo, podemos ser envolvidos por aquela noite da "diferença pura", pelo hermetismo jubiloso dos que traçam uma rígida linha divisória: os que não estão conosco então estão contra nós e devem ser excomungados. O desafio a ser enfrentado consiste em não abandonar os requisitos de uma linguagem em terceira pessoa, uma linguagem compreensível para uma comunidade universal de argumentação e orientada por algum princípio transcendental ou alguma estrutura semântica que ofereça uma inteligibilidade mínima à realidade em si mesma (McDowell, 2005). O que torna tal desafio verdadeiramente cruciante é que a psicanálise, nessa busca de inteligibilidade, não pode deixar de registrar o que a clínica não cessa de confirmar: o sujeito, ao falar e dar sentido ao vivido, bordeja a vertigem de um "furo" que suga e esvazia suas palavras.

\section{$3^{\text {a }}$ digressão conclusiva: para além do sentido}

Não há como prosseguir na argumentação senão tomando um outro rumo a demandar muito esforço e tempo para ser seguido. As poucas observações que se seguem não formam sequer uma pequena exposição como nas duas digressões anteriores, apenas visam a encerrar este artigo sem se configurar como uma conclusão. Uma digressão inconclusiva a recordar que a clínica psicanalítica sempre se desvia e, de algum modo, destitui as elaborações teóricas da própria psicanálise. O sujeito cioso de se assegurar de si mesmo não escapa de permanecer como ser-lançado (Geworfenheit) e decaído (Verfallen) no mundo, aprisionado na urdidura do ethos e da linguagem em que também não encontra o consolo de um sentido pleno porque, como diz Lacan, o furo que o atravessa (ce trou-là) bloqueia toda linguagem. A semântica é interrompida pelo choque do trauma, de um traumatismo universal que nos convida ao silêncio e ao recolhimento. Neles não podemos repousar, porque o gozo que fura o sentido também convida à linguagem e ao pensamento: "O pensamento é gozo. O que traz o discurso analítico é isto, que já estava começado na filosofia do ser - há gozo do ser" (Lacan, 1973, citado por Duportail, 2003; Lacan, 1985, p. 96). Mais do que um convite, essa imposição do gozo não pode nos servir de álibi para concluir "que toda hermenêutica é impossível" (Zizek, 2009, p. 149-183) e só há lugar para o discurso imaginário da ciência a travestir o real irredutível que habita o pensamento e a linguagem como uma realidade nua e crua a interditar todo sentido e diante da qual só resta o silêncio... Porém o silêncio da fadiga e da submissão. 


\section{Referências}

Ansermet, F. (2013). Elogio do incomensurável. Curinga, 35, 37-47.

Assoun, P.L. (1983). Introdução à epistemologia freudiana. Rio de janeiro: Imago.

Audi, R. (Org.). (2006). Dicionário de Filosofia de Cambridge. São Paulo: Paulus.

Brague, R. (1990). Le géocentrisme come humiliation de l'homme. In R. Brague \& J.F. Courtine (Org.). Hermenéutique et ontologie. (pp. 203-223). Paris: PUF.

Coreth, E., Ehlen, P., \& Schmid. (1987). La filosofia del siglo XIX. Barcelona: Herder.

Derrida, J., \& Roudinesco, E. (2004). De que amanhã... Diálogo. Rio de Janeiro: Jorge Zahar.

Drawin, C. R. (2004). A recusa da subjetividade: ideias preliminares para uma crítica do naturalismo. Psicologia em Revista, 10(15), 28-42.

Drawin, C. R. (2005). Oparadoxo da finitude: sobre o sentido ontoantropológico da psicanálise freudiana. (2 Vol). Tese de Doutorado, Universidade Federal de Minas Gerais, Belo Horizonte, MG, Brasil.

Drawin, C. R. (2009). Subjetividade e constituição ética da psicologia. In F Kyrillos Neto, R.O Silva, \& T. R. Oliveira. Subjetividade(s) e sociedade: contribuiçôes da Psicologia. (pp. 45-60). Belo Horizonte: Conselho Regional de Psicologia.

Duportail, G.-F. (2003). L“a priori” littéral: une approche phénoménologique de Lacan. Paris: Les Èditions Du Cerf.

Duportail, G. F. (2005). Intentionnalité et trauma: Levinas e Lacan. Paris: L'Harmattan.

Feyerabend, P. (2005). A conquista da abundância: uma história da abstração versus riqueza do ser. São Leopoldo: Editora Unisinos.

Freud, S. (1999a). Die Fixierung an das Trauma. In Vorlesungen zur Einführung in die Psychoanalyse. Gesammelte Werke XI. Frankfurt am Main: Fischer Taschenbuch Verlag. (Texto original publicado em 1917) 
Freud, S. (1999b). Eine Schwierigkeit der Psychoanalyse. Gesammelte Werke XII. Frankfurt am main: Fischer Taschenbur Verlag. (Texto original publicado em 1917)

Gadamer, H.-G. (1977). Verdad y método: fundamentos de uma hermenêutica filosófica. Salamanca: Sígueme.

Geertz, C. (2001). Nova luz sobre a antropologia. Rio de Janeiro: Jorge Zahar.

Heidegger, M. (2012). Ser e tempo. Campinas: Unicamp.

Herrero, J. (2012). Ser e Deus na filosofia sistemático-estrutural de Puntel. Sintese, 39 (124), 205-236.

Husserl, E. (1982). Investigaciones lógicas: tomo I. Madrid: Alianza.

Kant, I. (1985). Crítica da razão pura. Lisboa: Fundação Calouste Gulbenkian.

Lacan, J. (1985). O Seminário XX: mais, ainda. Rio de janeiro: Jorge Zahar.

Marion, J. L. (1975). Sur l'ontologie grise de Descartes. Paris: J. Vrin.

McDowell, J. (2005). Mente e mundo. Aparecida: Ideias e Letras.

Mutschler, H.D. (2008). Introdução à filosofia da natureza. São Paulo: Loyola.

Puntel, L. B. (2008). Estrutura e ser: um quadro referencial teórico para uma filosofia sistemática. São Leopoldo: Editora Unisinos.

Rocha, Z. (2004). Freud e a filosofia alemã na segunda metade do século XIX. Sintese, 31 (99), 45-64.

Röd, W. (1996). Der Weg der Philosophie. B.II. München: C.H. Beck.

Taylor, C. (1975). Hegel. Cambridge: Cambridge University Press.

Taylor, C. (1985). Philosophical papers: human agency and language. (Vol. 1). Cambridge: Cambridge University Press.

Thouard, D. (2004). Dilthey et la naissance de l'herméneutique en 1900. In: Worms, Fréderic (Org.). Le moment 1900 em Philosophie. (pp. 169-184). Lille: Les Presses Universitaires du Septentrion.

Zizek, Slavoj (2009). O trauma neuronal. In: A. Novaes, (Org.). A condição humana. São Paulo: Agir, Edições Sesc-SP. 